\title{
ADVANCED NUMERICAL PREDICTION OF UNREINFORCED U- SHAPED MASONRY WALLS LOADED OUT-OF-PLANE
}

\section{Scacco, Jacopo ${ }^{1}$; Silva, Luís C. ${ }^{2}$; Vasconcelos, Graça ${ }^{3}$; Milani, Gabriele ${ }^{1}$ and Lourenço, Paulo B. ${ }^{3}$}

\author{
${ }^{1}$ Department of Architecture Built Environment and Construction Engineering ABC, \\ Piazza Leonardo da Vinci 32, 20133 Milan, Italy \\ jacopo.scacco@polimi.it, gabriele.milani@polimi.it \\ ${ }^{2}$ ISISE, Faculty of Engineering, University Lusófona de Humanidades e Tecnologias, \\ Campo Grande, 1749-024 Lisbon, Portugal, \\ luis.silva@ulusofona.pt \\ ${ }^{3}$ ISISE, Department of Civil Engineering, University of Minho, \\ Azurém, 4800-058 Guimarães, Portugal, \\ graca@civil.uminho.pt,pbl@civil.uminho.pt
}

\begin{abstract}
The seismic vulnerability of unreinforced masonry structures is a relevant topic as they stand for one of the most typical building typologies in the world. Despite the effort carried out by researchers, further experimental campaigns can help to increase the level of knowledge on the most frequent collapse mechanism and to suggest the most adequate reinforcement technique for the specific case. In this context, we address here a study on a mixed construction technique, in particular a type of building with masonry walls and concrete slabs, the socalled "Placa" buildings. Such buildings are typical of the Lisbon region and were mainly erected from 1930 to 1960. In this period, there was low awareness about the effects of adding heavy slabs to the global and local behavior of masonry structures. The seismic vulnerability of such structures is high, which is relevant in a medium-high seismic hazard region such as Lisbon.

An experimental campaign will be performed at the University of Minho. The set-up comprises a U-shaped brick wall tested subjected to an out-of-plane load and three tests are planned to perform: an unreinforced and two (different) reinforced configurations.

In this paper, sensitivity analyses concerning the unreinforced wall are shown. The primary goal is the identification of the correct set-up that would allow the exploitation of the energy at the orthogonal connection without leading to undesirable rocking phenomena of the wall. In such a way, the subsequent application of the reinforcement will have a major role in vulnerability reduction.
\end{abstract}

Keywords: "Placa" buildings, brick walls, out-of-plane, micro-modeling, concrete damage plasticity. 


\section{INTRODUCTION}

Masonry structures are one of the most typical building typologies all over the world. Despite their great efficacy for sustaining gravity loads, they may suffer severe damage when subjected to horizontal loads coming from destructive events like earthquakes [1][2][3]. In recent years, several efforts were made to reduce the seismic vulnerability of such structures [4][5]. Indeed, not only for historical structures, but also for schools [6], hospitals and palaces that assume strategic importance during possible emergency management. Many of these buildings are relatively recent and can present a mixed technology, in which both masonry brick walls and reinforced concrete slabs are combined. A remarkable example of such construction typology is represented by the so-called "Placa" buildings, typical of the urban expansion of Lisbon in the period from 1930 to 1960.

In the progressive trend of introducing the reinforced concrete as the main structural element, the "Placa" buildings are characterized by brick walls, which stand as structural elements and reinforced concrete (RC) slabs. However, such a combination was realized in a period of insufficient awareness of the consequence of adding heavy concrete slabs (if compared to the timber ones) for the local and overall response of the buildings. Many deficiencies, along with inadequate construction details, can be typically found in "Placa" buildings, namely: i) internal structural irregularities, ii) limited capacity of the vertical elements against shear forces and bending, iii) a low number of vertical elements, iv) interruption between floor slabs and masonry walls affecting the rigid diaphragm behavior. All these aspects, combined with the increase of inertia loads because of concrete slabs, might lead to a marked seismic vulnerability, enhanced by the relevant seismic exposition of Lisbon.

An experimental campaign has been planned to investigate the local structural capacity of such buildings. The primary focus is the investigation of the out-of-plane capacity of the brick masonry walls that rarely have enough resistance against forces acting perpendicular, causing local collapse mechanism. Three U-shaped brick walls will be tested by applying a uniform pressure on the internal side of the wall (as done in [7]). The first configuration (unreinforced wall) will serve as a reference for the two subsequent reinforced configurations. To get a damage pattern that resembles what is observed in "Placa" buildings, particular care has been addressed in the design process of the experimental set-up. Indeed, in order to define the most effective strengthening solution and provide a fair comparison, the damage should spread mainly at the connection with the orthogonal walls. For this reason, it is necessary to avoid, or significantly postpone, any rocking of the U-shaped wall. In such a way, the improvements ensured by the reinforcement technique will be more noticeable. To this end, this paper summarizes distinct hypotheses for the geometry, load and boundary conditions on the unreinforced configuration. Damage patterns and load-displacement curves are presented in order to provide a comparison of the results.

\section{EXPERIMENTAL PLAN: AN OVERVIEW}

In this section, the experimental plan is exposed in each step. I will include: i) material characterization tests, ii) test on one scaled unreinforced configuration, iii) test on two different scaled reinforced configurations. Regarding the firsts, masonry wallets with an English-bond arrangement (the same as the U-shaped walls) have been built and will be tested according to the recommendations given in EN 1052-1:1998 [8] and EN 1052-2 [9]. In particular, 3 wallets will be tested under compression and 3 wallets under diagonal compression in order to define the in-plane behavior. The out-plane behavior will be investigated by testing 5 wallets under 
horizontal flexural tests and 5 wallets under vertical flexural tests. Along with these tests, a mechanical characterization of the mortar will be provided.

The geometric configuration of the walls has been defined to represent a typical façade and corresponding transversal walls of a 'Placa' building. As mentioned, bricks are arranged according to an English-bond arrangement with dimensions $250 \mathrm{~mm} \times 120 \mathrm{~mm} \times 60 \mathrm{~mm}$. The initial geometric dimensions of the set-up are: $3.24 \mathrm{~m}$ of façade wall length, walls' height of $1.40 \mathrm{~m}$, transversal walls' length of $1.20 \mathrm{~m}$ and thickness of $0.25 \mathrm{~m}$. However, as it will be clearer in the next Sections, such initial assumption resulted to not be sufficient for avoiding a rocking of all systems. So, a slight modification of such configuration is later justified.
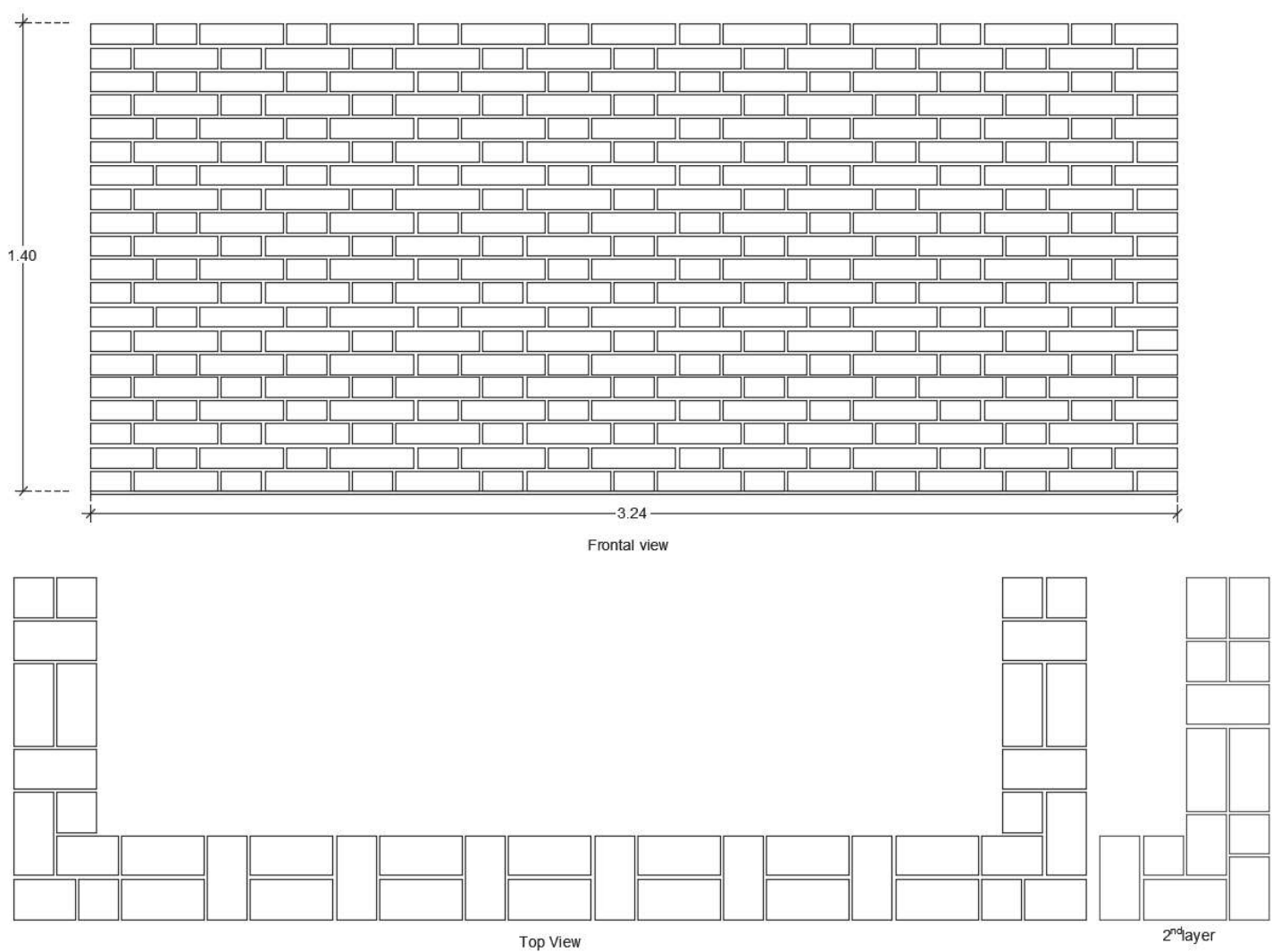

Figure 1 Frontal view (top) and top view (bottom) of the planned configuration.

The plan includes two different strengthening solutions are planned to be carried out: i) an anchored system between façade and transversal walls; ii) a textile reinforced mortar on the outer façade eventually coupled with the anchored system. In order to provide a further reference, the unreinforced wall will be reinforced after the damage and led to the collapse.

\section{NUMERICAL STRATEGY: A MICRO-MODELING APPROACH}

In the current prediction stage of the experimental campaign, a detailed heterogonous approach has been picked to reproduce accurately the failure modes. In such an approach, the bricks and mortar joints are modeled separately with contiguous 3D elements. No interfaces are interposed between them and the non-linear mechanical properties are exclusively lumped at the joints, addressing only elastic properties to the bricks (as done in [10-12]). Such simplification is reasonable as the good mechanical properties of bricks and the weak capacity of the mortar. Specifically, the mortar intended to be used in the tests is characterized as Mortar5, with a compressive strength equal to $5 \mathrm{MPa}$. All the analyses are carried out in the FE-based software Abaqus and non-linearities are addressed through the already available constitutive 
model Concrete Damage Plasticity. In such a way, it is possible to input a differential behavior in compression and tension and define a specific softening law. In this predictive stage, a tensile strength equal to $0.2 \mathrm{MPa}$ has been addressed to the mortar along with fracture energy of $0.02 \mathrm{~N} / \mathrm{mm}$. Regarding the mesh, taking advantage of the symmetry of the setup, a half wall has been modeled. The average size of the 3D brick elements is around 10-20 mm leading to an overall number of nodes around 140000.

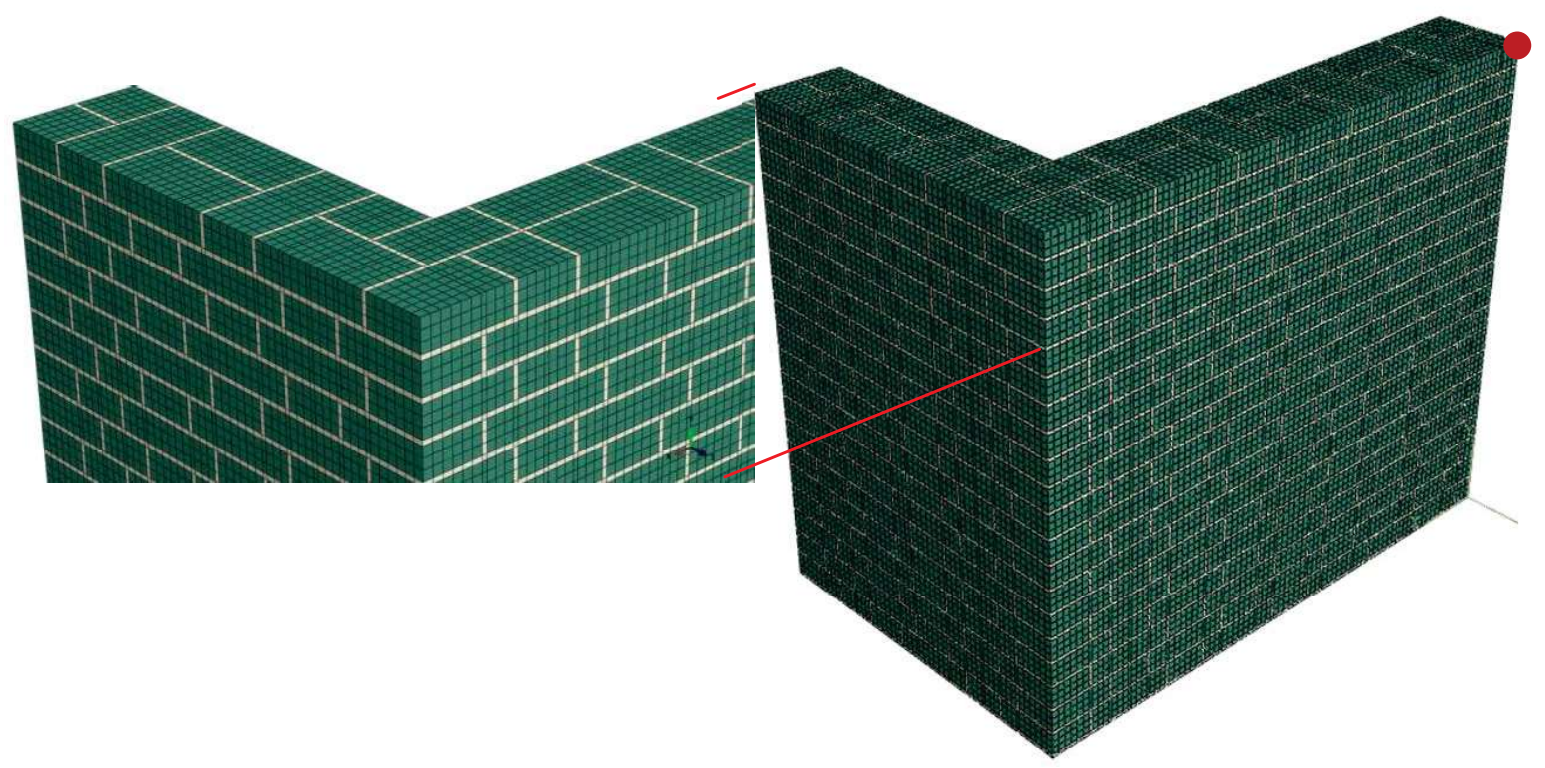

Figure 2 Model in Abaqus of half wall and mesh detail.

The analyses are carried out by applying a perpendicular uniform pressure on the internal side of the main wall in order to simulate the load transferred from the airbag that will be used in the experimentation (same procedure followed in [7]). In this way, the analyses are all performed under load control and the arch-length algorithm is employed for obtaining the softening response of the structure. Fixed boundary conditions are imposed at the bottom of the wall where a mortar layer (with the same mechanical properties used for the joints) is posed.

\section{NUMERICAL RESPONSE OF THE U-SHAPED URM WALL: PARAMETRIC ANALYSES}

The sensitivity (in terms of geometry, pre-stress level and boundary conditions) numerical analyses that will be shown in the next Sections are applied only at the unreinforced masonry case. Indeed, the main goal of the present work is the definition of the correct set-up with the view of applying different strengthening techniques on the same configuration in a subsequent step.

The first parametric analysis concerns the amount of pre-stress that is necessary to impose on the side walls in order to avoid or postpone any rocking phenomena. In Figure $3 \mathrm{a}$ it is provided a comparison of the load-displacement curves related to different values of the imposed pre-stress. The control point is picked exactly at the top middle of the wall (red circle in Figure 1). It is important to highlight that the global loads to which reference is made are related to the half specimen. As it is noticeable, the U-shaped wall tested with no pressure on the top of the side walls is characterized by a marked softening behavior. However, as shown in Figure $3 \mathrm{~b}$, such behavior is associated with a rocking phenomenon that is not desirable. The softening branch is strongly reduced at the increase of the pre-stress applied, reaching a plateau when a pre-stress of $100 \mathrm{kPa}$ is considered. In fact, in Figure 3c, it is possible to appreciate the reduction of the damage at the bottom of the wall. However, its extent is still too clear and further sensitivity analyses are required. 


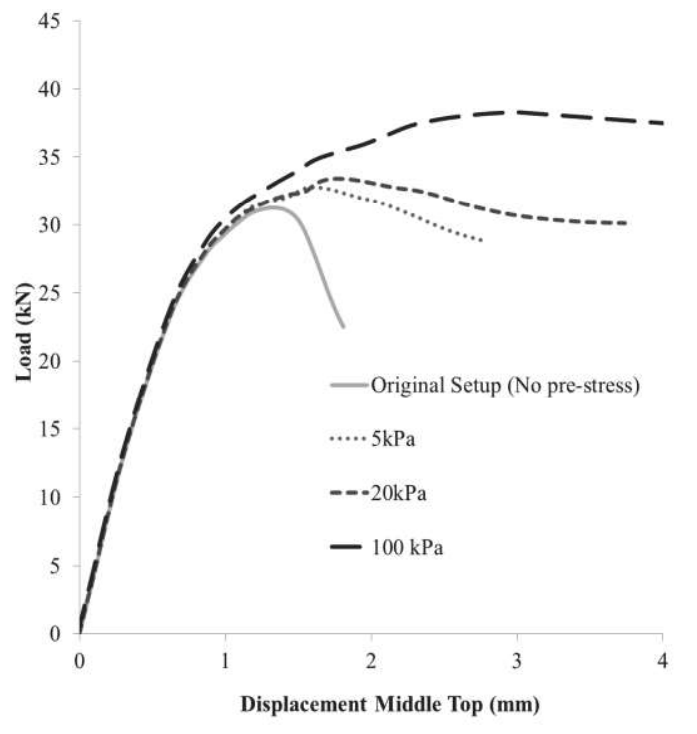

(a)

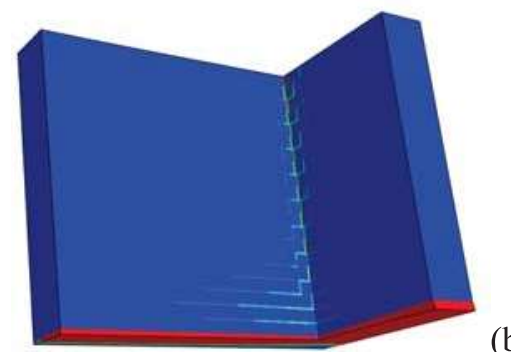

(b)

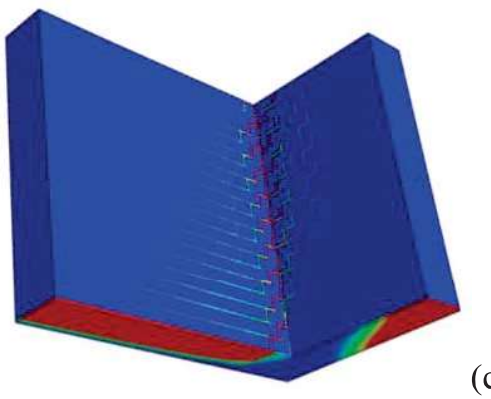

(c)

Figure 3 Load-displacement curves related to the wall in its original configuration by applying different values of pressure (a); damage configuration of the wall without pre-stress(b); damage configuration of the wall subjected to a pressure of $100 \mathrm{kPa}(\mathrm{c})$.

The next sensitivity analyses are focused on the possibility to impose further constraints. In Figure 4 it is provided a qualitative overview of the results obtained. In particular, in Figure 4a the back face of the side wall is constrained. This hypothesis can be implemented by embedding the back portion of the lateral wall in U-shaped steel beams (a similar setup can be found in [13]). In such a way, the rotation of the side walls is prevented and the damage spread mostly at the connection as required. A similar result can be achieved by imposing a steel beam above the top back corner of the lateral walls. As it is noticeable in Figure $4 \mathrm{~b}$ the damage pattern can be superimposed to the previous case. These strategies are highly efficient but, on the other hand, the control of the load attained by such constraints might be complicated.

In Figure 4c-d it is shown an attempt of modifying the boundary conditions at the base of the wall. In Figure 4c, the first layer of brick and mortar is furtherly constrained, but in such a way the rocking trend is only delayed. In Figure $4 \mathrm{~d}$, a different hypothesis has been made. In this case, the central wall is considered only supported at the base (a layer of sand can serve the purpose) leading to a single curvature bending moment. However, the damage pattern is concentrated mainly at the connection at the base of the walls
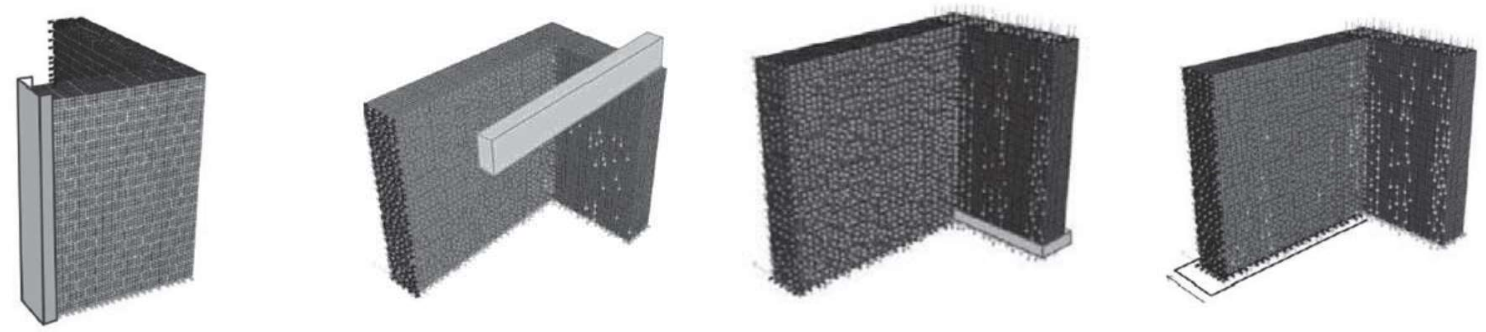


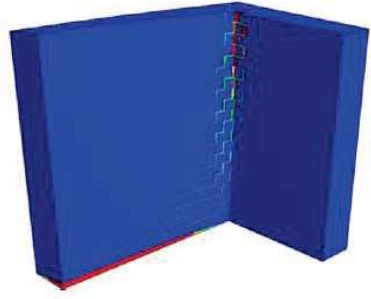

(a)

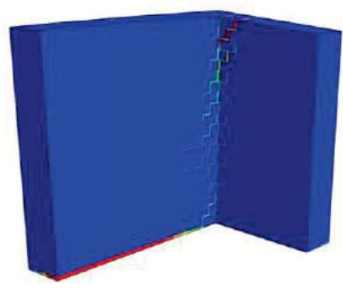

(b)

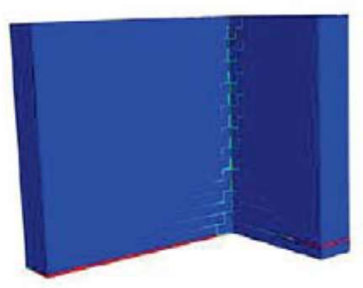

(c)

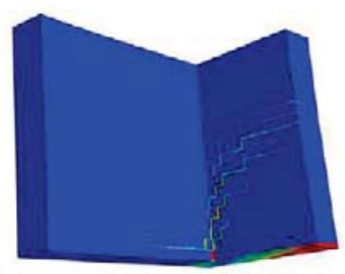

(d)

Figure 4 Boundary condition applied at the back face of the side wall and related damage pattern (a); boundary condition applied at the top of the side wall and related damage pattern (b); boundary condition applied at the bottom (fixing two layers of bricks) of the side wall and related damage pattern (c); boundary condition released at the bottom of the main wall and related damage pattern (d).

From the previous analyses, it seems evident the necessity to change the original geometric configuration presented in Section 2. So, a parametric analysis is conducted on the length of the main wall and side walls. These lengths are increased to $25 \mathrm{~cm}$ (model "SWL_25cm" that stands for Side Wall Longer of $25 \mathrm{~cm}$ ) and to $50 \mathrm{~cm}$ (model "SWL_50cm"). The main wall is modified by adding $80 \mathrm{~cm}$ and $120 \mathrm{~cm}$ (model "402_SWO") that stands for the main wall of $402 \mathrm{~cm}$ and the Side Wall Original and model "442 SWO"). Also, a combination of both modifications is provided in the models "402_SWL_25cm" and "442_SWL_25cm". In all the cases a vertical pre-stress of $20 \mathrm{kPa}$ is imposed.

In Figure 5 the global responses of all the models are reported. It is interesting to notice the strong enhancement that the extension of the side walls can provide (Fig. 5a). From a comparison of the capacity curves, the outcomes are very similar to the one obtained when a vertical pre-stress of $100 \mathrm{kPa}$ is imposed. However, comparing the damage pattern (Fig. 6a-b), the rocking behavior is much less evident. Moreover, no evident differences can be noticed among the curves related to the models SWL_25 cm and SWL_50 $5 \mathrm{~cm}$ but as shown in Figures $6 \mathrm{a}$ and $6 \mathrm{~b}$ the damage at the base of the side wall is almost absent in this case. This might have huge relevance when the reinforced configurations will be treated.

Figure $5 \mathrm{~b}$ provides the results related to the extension of the main wall (also in combination with an extension of $25 \mathrm{~cm}$ of the side walls). It is quite evident how increasing the length of the side walls is much more effective than extending the longitudinal dimension of the main wall. Moreover, this strategy would require much more material for the construction of the walls without leading to further improvements (see the comparison of the damage pattern in Figure 6a and Figure 6c). 


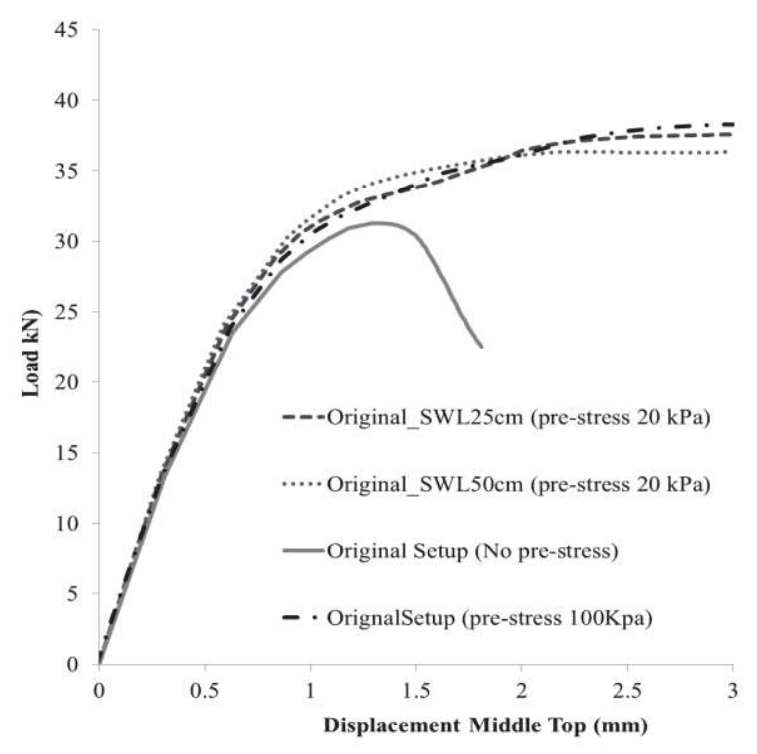

(a)

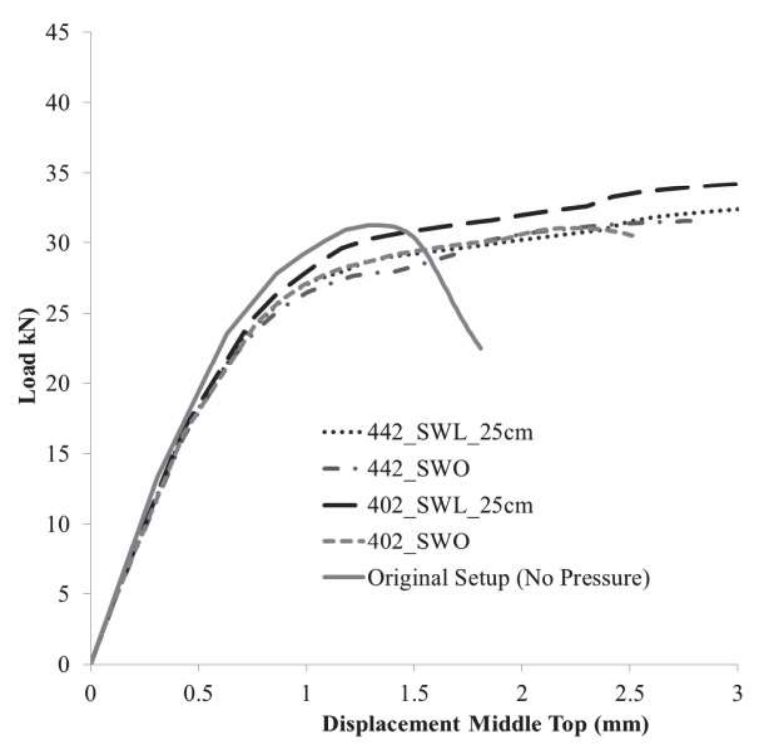

(b)

Figure 5 Load-displacement curves related to the original setup by changing the length of the side walls (a); Load-displacement curves of the original setup by changing the length of the main and of the side walls.

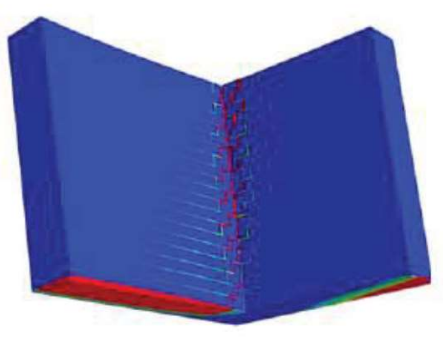

(a)

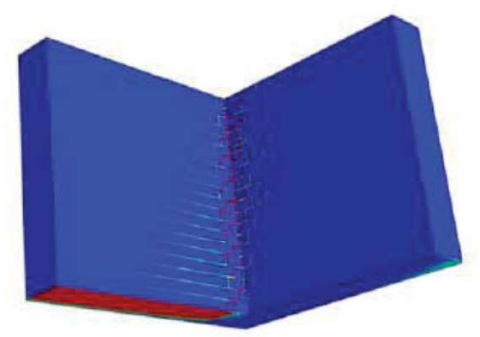

(b)

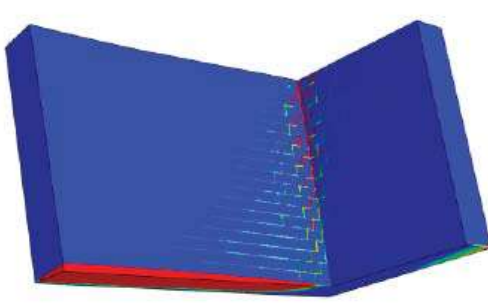

(c)

Figure 6 Damage pattern of the model SWL_25cm (a); Damage pattern of the model SWL_50cm (b); Damage pattern of the model 442 SWL_25cm (c).

\section{CONCLUSIONS}

The paper summarizes preliminary analyses conducted on an unreinforced brick masonry wall. The main scope was the definition of the correct set-up in terms of geometric configuration, the load applied and boundary conditions for upcoming experimental tests that will be performed at the facilities of the University of Minho in Guimarães.

The experimental campaign will focus on the seismic vulnerability and possible strengthening solutions for building realized with a mixed technology: masonry walls and RC slabs. The socalled "Placa" buildings are a typical example of such configuration, and particularly vulnerable as mainly spread in the Lisbon region. In order to resemble this structural typology, a U-shaped brick wall has been conceived. Several parametric analyses have been carried out to highlight the parameters that have more influence on both the global behavior and collapse mechanism. The different proposed scenarios revealed the necessity to adapt the initially planned configuration to prevent any rocking mechanism of the structure that would be undesirable. In fact, the occurrence of such a collapse mechanism would prevent the spread of damage at the connection between transversal walls, which will the point of more interest when defining the strengthening solutions will be discussed. In the upcoming numerical analyses concerning the reinforced scenarios, the 
composite materials might be added using a detailed micro-modeling [10][14] or through a simplified approach [15]. Whereas, the anchors might be introduced explicitly in the model or through truss FEs [7] avoiding an increase in the computational demand.

\section{REFERENCES}

[1] Bianchini N, Mendes N, Lourenço PB. Seismic evaluation of Bagan heritage site ( Myanmar ): The Loka-Hteik-Pan temple. Structures, 24, 905-21 (2020).

[2] Giordano E, Clementi F, Nespeca A, Lenci S. Damage Assessment by Numerical Modeling of Sant 'Agostino' s Sanctuary in Offida During the Central Italy 2016 2017 Seismic Sequence. 4, 1-17 (2019).

[3] Micelli F, Cascardi A. Structural assessment and seismic analysis of a 14 th century masonry tower. Eng. Fail. Anal., 107, (2020).

[4] Aşıkoğlu A, Avşar Ö, Lourenço PB, Silva LC. Effectiveness of seismic retrofitting of a historical masonry structure: Kütahya Kurşunlu Mosque, Turkey. Bull. Earthq. Eng., 17, 3365-95 (2019).

[5] Mosoarca M, Apostol I, Keller A, Formisano A. Consolidation methods of Romanian historical building with composite materials. Key Eng. Mater., 747 KEM, 406-13 (2017).

[6] Formisano A, Iaquinandi A, Mazzolani FM. Seismic retrofitting by FRP of a school building damaged by Emilia-Romagna earthquake. Key Eng. Mater., 624, 106-13 (2015).

[7] Murano A, Ortega J, Vasconcelos G, Rodrigues H. In fl uence of traditional earthquake-resistant techniques on the out-of-plane behaviour of stone masonry walls : Experimental and numerical assessment. Eng. Struct., 201, 109815 (2019).

[8] EN 1052-1. EN 1052-1: Methods of test for masonry, Part 1: Determination of compressive strength, European Committee for Standardization, Bruxelles, Belgium.

[9] CEN. EN 1052-2, European norm for methods of test for masonry - Part 2: Determination of flexural strength, 2000.

[10] Scacco J, Ghiassi B, Milani G, Lourenço PB. A fast modeling approach for numerical analysis of unreinforced and FRCM reinforced masonry walls under out-of-plane loading. Compos. Part B, 180, (2020).

[11] Lourenço PB, Silva LC. Computational applications in masonry structures: from the meso-scale to the super-large/super-complex. Int. J. Multiscale Comput. Eng., 18, 1-30 (2020).

[12] Silva LC, Lourenço PB, Milani G. Numerical homogenization-based seismic assessment of an English-bond masonry prototype: Structural level application. Earthq. Eng. Struct. Dyn., 49, 841-62 (2020).

[13] Prota A, Marcari G, Fabbrocino G, Manfredi G, Aldea C. Experimental In-Plane Behavior of Tuff Masonry Strengthened with Cementitious Matrix-Grid Composites. J. Compos. Constr., 10, 223-33 (2006).

[14] Scacco J, Milani G, Lourenço PB. A micro-modeling approach for the prediction of TRM bond performance on curved masonry substrates. Compos. Struct., 256, 113065 (2021).

[15] Bertolesi E, Milani G, Poggi C. Simple holonomic homogenization model for the nonlinear static analysis of in-plane loaded masonry walls strengthened with FRCM composites. Compos. Struct., 158, 291-307 (2016). 